\title{
Hardness in Drinking-Water, its Sources, its Effects on Humans and its Household Treatment
}

\begin{abstract}
Keywords: Hard water; Polyvalent; Seepage; Bathtub ring; Nephrolithiasis; Conditioning

Abstract

Hard Water is very dangerous to health of human beings. It causes many diseases in humans. It also disturbs the industries. It is not safe to drink, also for other domestic purposes. The hardness in water is caused by polyvalent metallic ions from sedimentary rocks, seepage and runoff from soils. Calcium and magnesium, the two principal ions, are present in many sedimentary rocks, are the principal ions causing Water Hardness. They are also common essential minera constituents of food. Excess intakes of calcium and magnesium can increase the risks of osteoporosis, nephrolithiasis, colorectal cancer, hypertension and stroke, coronary artery disease, insulin resistance and obesity. Magnesium deficiency has been implicated in the pathogenesis of hypertension, with some epidemiological and experimental studies demonstrating a negative correlation between blood pressure and serum magnesium levels. This Hard Water containing these ions can be treated at primary level for household purposes. Point-of-entry ion exchange (water softener) devices are used in some households to remove hardness (calcium, magnesium) and iron from water.
\end{abstract}

\section{Introduction}

Water Hardness (WHs) is the traditional measure of the capacity of water to react with soap, Hard Water (HW) requiring considerably more soap to produce lather. HW often produces a noticeable deposit of precipitate (e.g. insoluble metals, soaps or salts) in containers, including "bathtub ring". It is not caused by a single substance but by a variety of dissolved polyvalent metallic ions, predominantly calcium and magnesium cations, although other cations (e.g. aluminum, barium, iron, manganese, strontium and zinc) also contribute.

WHs is most commonly expressed as milligrams of calcium carbonate equivalent per litre. Water containing calcium carbonate at concentrations below $60 \mathrm{mg} / \mathrm{l}$ is generally considered as soft; 60 $120 \mathrm{mg} / \mathrm{l}$, moderately hard; $120-180 \mathrm{mg} / \mathrm{l}$, hard; and more than 180 $\mathrm{mg} / \mathrm{l}$, very hard. Although hardness is caused by cations, it may also be discussed in terms of carbonate (temporary) and non-carbonate (permanent) hardness.

The principal natural sources of hardness in water are dissolved polyvalent metallic ions from sedimentary rocks, seepage and run off from soils. Calcium and magnesium, the two principal ions, are present in many sedimentary rocks, the most common being limestone and chalk. They are also common essential mineral constituents of food. As mentioned above, a minor contribution to the total hardness of water is also made by other polyvalent ions, such as aluminum, barium, iron, manganese, strontium and zinc. The major individual role of these principal ions is elaborated below.

\section{Role of calcium in WHs}

Calcium is unique among nutrients, in that the body's reserve is also functional; increasing bone mass is linearly related to reduction
Journal of

Chemistry \& Applications

\section{Sana Akram and Fazal-ur-Rehman*}

Department of Chemistry, University of Education, Lahore-Vehari Campus, Pakistan

\section{Address for Correspondence}

M. Fazal-ur-Rehman, Department of Chemistry, University of Education, LahoreVehari Campus, Vehari (61100), Punjab, Pakistan, E-mail: fazalurrehman517@ gmail.com; sanakram368@gmail.com

Submission: 09 May, 2018

Accepted: 08 June, 2018

Published: 14 June, 2018

Copyright: (c) 2018 Akram S, et al. This is an open access article distributed under the Creative Commons Attribution License, which permits unrestricted use, distribution, and reproduction in any medium, provided the original work is properly cited.

in fracture risk. The total body stores are on the order of $1200 \mathrm{~g}$, with about $99 \%$ in bones and teeth. A large body of primary evidence from randomized controlled trials shows that increasing calcium intake, especially in those who have had habitually low calcium intakes, increases bone mass during growth and reduces bone loss and fracture risk late in life [1].

Excess intakes of calcium can increase the risks of osteoporosis, nephrolithiasis (kidney stones), colorectal cancer, hypertension and stroke, coronary artery disease, insulin resistance and obesity [2]. Most of these disorders have treatments, but not cures. Owing to a lack of compelling evidence for the role of calcium as a contributory element in relation to these diseases, estimates of calcium requirement have been made on the basis of bone health outcomes, with the goal of optimizing bone mineral density.

Osteoporosis is one of the most prevalent of age-related diseases [3]. Calcium and vitamin D are jointly beneficial in increasing bone mass.

Epidemiological evidence indicates that dietary calcium reduces the incidence of kidney stones. In contrast, the results of a large randomized trial suggest an increased risk of kidney stones associated with calcium supplements, possibly because the calcium was ingested as a bolus and not with food or the supplements were taken by those who exceeded the upper intake level of $2500 \mathrm{mg}$ /day [4].

Hypertension, although, is multifactorial in origin, adequate calcium intake has been associated with lowered risk of elevated blood pressure in some, but not all, studies [5]. A clear mechanism has not been identified, although electrolytes probably play a role. Dairy products, more than calcium per se, has been associated with reduced blood pressure in randomized prospective studies and with reduced risk of stroke in prospective studies. Those individuals who avoid dairy products or lack access to them throughout life may be at increased risk of calcium deficiency. Formula-fed infants will not normally be at risk from deficient or excess amounts of calcium, as even extremely low or high calcium concentrations in water would not lead to absorption of non-physiological amounts of calcium from 
Citation: Akram S, Rehman F. Hardness in Drinking-Water, its Sources, its Effects on Humans and its Household Treatment. J Chem Applications. 2018;4(1): 4

ISSN: $2380-5021$

infant formula reconstituted with the water. If, however, other food sources are used that do not provide the calcium content of fullstrength formula, then water may represent an important source of the mineral for the infants.

When calcium is absorbed in excess of need, the excess is excreted by the kidney in healthy people who do not have renal impairment. Concern for excess calcium intake is directed primarily to those who are prone to milk alkali syndrome (the simultaneous presence of hypercalcaemia, metabolic alkalosis and renal insufficiency) and hypercalcaemia [6].

\section{Role of magnesium in WHs}

Magnesium is the fourth most abundant cation in the body and the second most abundant cation in intracellular fluid. It is a cofactor for some 350 cellular enzymes, many of which are involved in energy metabolism [7]. It is also involved in protein and nucleic acid synthesis and is needed for normal vascular tone and insulin sensitivity. Total body stores are on the order of $25 \mathrm{~g}$, with about $60 \%$ in bone [8]. Total body burden is difficult to quantify, because only a small portion is in blood or fluids, and it can bevariable.

Low magnesium levels are associated with endothelial dysfunction, increased vascular reactions, elevated circulating levels of C-reactive protein (a proinflammatory marker that is a risk factor for coronary heart disease) and decreased insulin sensitivity. Low magnesium status has been implicated in hypertension, coronary heart disease, type 2 diabetes mellitus and metabolic syndrome.

Magnesium deficiency has been implicated in the pathogenesis of hypertension, with some epidemiological and experimental studies demonstrating a negative correlation between blood pressure and serum magnesium levels. However, data from clinical studies have been less convincing. Cardiac arrhythmias of ventricular and atrial origin have been reported in patients with hypomagnesaemia and in postmenopausal women in controlled diet studies. Indeed, a serious cardiac arrhythmia, Torsade de Pointes, is treated with intravenous magnesium therapy [9].

Pre-eclampsia (defined as hypertension after 20 weeks of gestation) with proteinuria has been treated with magnesium salts for many decades [10]. A recent trial using magnesium sulfate showed a $50 \%$ decreased risk of eclampsia. Animal studies have documented an inverse (protective) relationship between magnesium intake and the rate or incidence of atherosclerosis. In humans, there is evidence for an inverse (protective) relationship between magnesium and coronary heart disease mortality. Three cross-sectional studies have now documented an inverse relationship between the concentration of $\mathrm{C}$-reactive protein and magnesium intake and serum magnesium concentration, suggesting that magnesium may have an antiinflammatory effect.

Several studies have documented the importance of magnesium in type 2 diabetes mellitus. Two recent studies have documented an inverse (protective) relationship between magnesium intake and risk of developing type 2 diabetes mellitus. Oral magnesium supplementation improves insulin sensitivity and metabolic control in type 2 diabetes mellitus [11].

Alcoholism and intestinal malabsorption are conditions associated with magnesium deficiency [12]. Some drugs, such as certain diuretics, some antibiotics and some chemotherapy treatments, increase the loss of magnesium through the kidney; therefore, those patients should have magnesium supplementation as part of their therapy.

The major cause of hypermagnesaemia is renal insufficiency associated with a significantly decreased ability to excrete magnesium. Increased intake of magnesium salts may cause a temporary adaptable change in bowel habits (diarrhoea), but seldom causes hypermagnesaemia in persons with normal kidney function. Drinking-water in which both magnesium and sulfate are present at high concentrations (above approximately $250 \mathrm{mg} / \mathrm{l} \mathrm{each}$ ) can have a laxative effect, although data suggest that consumers adapt to these levels as exposures continue [13]. Laxative effects have also been associated with excess intake of magnesium taken in the form of supplements, but not with magnesium in diet.

\section{Other health effects}

Exposure to HW has been suggested to be a risk factor that could exacerbate eczema. The environment plays an important part in the etiology of atopic eczema [14], but specific causes are unknown. Numerous factors have been associated with eczema flare-up, including dust, nylon, shampoo, sweating, swimming and wool [15].

A suggested explanation relative to HW is that increased soap usage in HW results in metal or soap salt residues on the skin (or on clothes) that are not easily rinsed off and that lead to contact irritation [16]. There are reports of a relationship between both 1-year and lifetime prevalence of atopic eczema and WHs among primaryschool children. Eczema prevalence trends in the secondary-school population were not significant. Additional studies are under way.

\section{Other factors}

Taste of water: Dissolved minerals contribute to the taste of drinking-water to varying degrees. Acceptability of water will usually depend on the individual user's taste and familiarity [17]. Demineralized water tends to have a flat taste, and producers of demineralized bottled or packaged water often add some minerals for taste. Some bottled mineral waters have exceptionally high mineral concentrations and appeal to some consumers, but would not be considered acceptable for most public drinking water supplies [18]. Concentrations of calcium and magnesium and other dissolved solids in water that are detectable by consumers are manageable by treatment or blending in public drinking-waters [19].

Conditioning: When conditioning is done, the target is normally to achieve bicarbonate equilibrium and suitable $\mathrm{pH}$ and alkalinity. Other ions, such as sulfate, nitrate and chloride, can be implicated in corrosivity. Central water softening treatment usually involves lime (hydrated calcium oxide) or lime soda (lime plus sodium carbonate) softening and is commonly practised. These chemicals increase the precipitation of the calcium and magnesium carbonate, reducing the calcium hardness of the treated water [20]. These waters are balanced to minimize post-precipitation of lime and should be stabilized as needed to control corrosivity. There are significant differences between naturally soft water, including rainwater or soft deionized water, and water that has been softened by cation exchange, where in 
Citation: Akram S, Rehman F. Hardness in Drinking-Water, its Sources, its Effects on Humans and its Household Treatment. J Chem Applications. 2018;4(1): 4

ISSN: 2380-5021

the divalent cations $\left(\mathrm{Ca}^{2+}, \mathrm{Mg}^{2+}\right.$, etc. $)$ have been replaced by sodium. Cation exchange-softened water, although containing substantial amounts of sodium and chloride, is not necessarily corrosive. Naturally soft waters also require similar stabilization and corrosion reduction treatment prior to distribution.

\section{Treatment}

\section{Household water treatment}

Point-of-entry ion exchange (water softener) devices are used in some households to remove hardness (calcium, magnesium) and iron from water. Each divalent ion (e.g. $\mathrm{Ca}^{2+}$ or $\mathrm{Mg}^{2+}$ ) in the water is replaced by two sodium ions. Softening will have several aesthetically beneficial effects inside the home, such as reducing scaling in pipes, fixtures and water heaters and improving laundry and washing characteristics, but it also increases the sodium (and chloride) content of the drinking-water. Consumption of calcium and magnesium in drinking-water will, of course, be lower unless the water that is consumed is not softened or is remineralized [21]. Pointof-use reverse osmosis and distilling devices remove virtually all the minerals from the input water, and they can remove several types of potential trace-level contaminants that may be present, as well as removing nutrient minerals. While this treatment, the resultant drinking-water is devoid of minerals. So, use of these devices may result in the reduction of the overall intake of nutrient minerals by the consumers in the households [22].

Users of these devices should be made aware of the changes in mineral composition that arise and the possible consequences for total nutrient intake. For example, those who sell or install these devices may be encouraged to bring to the attention of the users of these devices the possibility of reduced intake of minerals. One approach to ensure that the water used for drinking and cooking is not demineralized is to soften only the hot water line at the entry to the hot water heater, which provides several benefits and also reduces costs. Additionally, the manufacturers of these water softeners may provide a suitable bypass of a portion of this water to maintain some level of these minerals in the water actually consumed (e.g. to a kitchen tap) or develop and add an appropriate remineralizing unit in the water line prior to the point of consumption [23].

\section{Conclusion}

Natural and treated waters have a wide range of mineral content, from very low levels in rain waters and naturally soft and softened water to moderate and very high levels in naturally HWs and waters with high total dissolved solids content [24]. Bottled and packaged waters can be naturally mineralized or naturally soft or demineralized. Thus, the mineral consumption from drinking-water and cooking water will vary widely, depending upon location, treatment and water source.

The degree of hardness of drinking-water is important for aesthetic acceptability by consumers and for economic and operational considerations. Many HWs are softened for those reasons using several applicable technologies, and the mineral composition will be significantly affected. The choice for the most appropriate conditioning technology will depend on local circumstances (e.g. water quality issues, piping materials, corrosion). Some softening is provided at the central treatment plant, and some is provided in individual homes as a consumer preference. Modification of calcium and magnesium concentrations in drinking-water for health reasons should comply with the technical requirements to provide water suitable for distribution and should not compromise disinfection [25]. Based on local circumstances and prevalent deficiencies, water suppliers and public health authorities may wish to further modify drinking-water composition in light of overall mineral nutrition.

Consumers should be informed of the mineral composition of their water, whether it is or is not modified. The contribution of drinking-water minerals to mineral nutrition should be considered where changes in supply are proposed or where less traditional sources, such as recycled water, seawater or brackish water, are processed and exploited for drinking-water [26]. All of those techniques require that the water be stabilized prior to distribution, and addition of lime is a common and low-cost method. Drinkingwater may be a contributor of calcium and magnesium in the diet and could be important for those who are marginal for calcium and magnesium intake. Where drinking-water supplies are supplemented with or replaced by demineralized water that requires conditioning, consideration should be given to adding calcium and magnesium salts to achieve concentrations similar to those that the population received from the original supply. As lime softening is commonly practised, addition of calcium and sometimes magnesium is a common practice for technical reasons and actually also adds calcium and often magnesium, which may be beneficial to dietary intake [27]. Naturally soft water also often requires stabilization for corrosion control, and similar mineralization treatments should also be considered.

Although there is some evidence from epidemiological studies for a protective effect of magnesium or hardness on cardiovascular mortality, the evidence is being debated and does not prove causality. Further studies are being conducted. There are insufficient data to suggest either minimum or maximum concentrations of minerals at this time, and so no guideline values are proposed.

\section{References}

1. Smith RC (1959) Evaluation of various methods and reagents for total hardness and calcium hardness in water. lowa State J. Sci, 34: p. 81.

2. Ternan J (1972) Comments on the use of a calcium hardness variability index in the study of carbonate aquifers: with reference to the central Pennines, England. J Hydrol 16: 317-321.

3. Kanis JA, Melton LJ $3^{\text {rd }}$, Christiansen C, Johnston CC, Khaltaev N (1994) The diagnosis of osteoporosis. J Bone Miner Res 9: 1137-1141.

4. (2000) Osteoporosis Prevention, Diagnosis, and Therapy. NIH consensus statement 17: 1-36.

5. Verdecchia P, Porcellati C, Schillaci G, Borgioni C, Ciucci A, et al. (1994) Ambulatory blood pressure. An independent predictor of prognosis in essential hypertension. Hypertension 24: 793-801.

6. Sowers JR, Epstein M, Frohlich ED (2001) Diabetes, hypertension, and cardiovascular disease: an update. Hypertension 37: 1053-1059.

7. Magee L, Sawchuck D, Synnes A, Dadelszen VP (2011) SOGC Clinical Practice Guideline. Magnesium sulphate for fetal neuroprotection. J Obstet Gynaecol Can 33: 516-529.

8. Neri LC, Johansen HL, Hewitt D, Marier J, Langner N (1985) Magnesium and certain other elements and cardiovascular disease. Sci Total Environ 42: 49-75.

9. Ong CN, Grandjean AC, Heaney RP (2009) The mineral composition of 
Citation: Akram S, Rehman F. Hardness in Drinking-Water, its Sources, its Effects on Humans and its Household Treatment. J Chem Applications. 2018;4(1): 4 .

ISSN: $2380-5021$

water and its contribution to calcium and magnesium intake. In: Calcium and Magnesium in Drinking-water. pp. 37

10. Roberts JM, Redman CW (1993) Pre-eclampsia: more than pregnancyinduced hypertension. Lancet 341: 1447-1451.

11. American Diabetes Association (2010) Diagnosis and classification of diabetes mellitus. Diabetes care 33(Suppl 1): S62-S69.

12. Halsted CH, Robles EA, Mezey E (1973) Intestinal malabsorption in folatedeficient alcoholics. Gastroenterology 64: 526-532.

13. Roggin GM, Kater RMH, Tobon F, Iber FL (1969) Malabsorption in the chronic alcoholic. Annals of Internal Medicine 70: 1070-1070.

14. Mezey E (1975) Intestinal function in chronic alcoholism. Ann N Y Acad Sci 252: $215-227$.

15. Ozdemir A, Utkualp N, Palloş A, Water hardness and health. Environment and ecology at the beginning of $21^{\text {st }}$ century, pp. 717

16. Marier JR, Neri LC, Anderson TW (1979) Water hardness, human health, and the importance of magnesium.

17. Bartoshuk LM (1968) Water taste in man. Perception \& Psychophysics 3: 69-72.

18. Bartoshuk L, Harned MA, Parks LH (1971) Taste of water in the cat: effects on sucrose preference. Science 171: 699-701.
19. McBurney DH, Shick TR (1971) Taste and water taste of twenty-six compounds for man. Perception \& Psychophysics 10: 249-252.

20. Sanderson CH (1976) Water conditioning apparatus. US3951807A, Google Patent

21. Sanzenbacher WA (1968) Water-conditioning unit. US3392837A, Google Patents.

22. Caldwell DH, Lawrence WB (1953) Water softening and conditioning problems. Ind Eng Chem 45: 535-548.

23. Edzwald JK (2010) Water quality and treatment: a handbook on drinking water, $6^{\text {th }}$ edn. McGraw Hill Group.

24. Sontheimer H, Crittenden JC, Summers RS (1988) Activated carbon for water treatment. American water works association. pp. 722.

25. Athithan S, Francis T, Ramanathan N, Ramadhas V (2001) A note on monoculture of Penaeus monodon in a hardwater seasonal pond. Naga, The ICLARM Quarterly 24: 14-15.

26. Cameron BA (2011) Detergent considerations for consumers: laundering in hard water-How much extra detergent is required. J Extension 49: 1-11.

27. Curran WS, McGlamery, Liebl RA, Lingenfelter DD (1999) Adjuvants for enhancing herbicide performance. Agronomy Facts 37: 1-12.

\section{Acknowledgement}

This review paper explores the causes of hardness water, sources of hardness, its typical effects on health of livings, and its primary treatment for use of household purposes. 